\title{
Preventing the spread of COVID-19 from chest drains
}

\author{
PY Lung, RN, MSc, SY Au *, MB, BS, FHKAM (Medicine), KM Fong, MB, ChB, FHKAM (Medicine), CH Yeung, RN, MSc, \\ Ruby HM Wong, MSc, FHKAN, YN Tsang, MSc, FHKAN, George WY Ng, MB, BS, FHKAM (Medicine)
}

This article was published on 11 Aug 2021 at www.hkmj.org.
Department of Intensive Care, Queen Elizabeth Hospital, Hong Kong

*Corresponding author: h0145237@gmail.com

Hong Kong Med J 2021;27:306-8

https://doi.org/10.12809/hkmj209149

\section{Introduction}

For a patient with coronavirus disease 2019 (COVID-19) with chest drain inserted for pneumothorax, air leakage from the chest drain system, which is not a closed system, can aerosolise when bubbling through the underwater seal and cause viral spreading. ${ }^{1}$ There are limited reports suggesting means to prevent viral spread by modifying the chest drain systems for patients with COVID-19. ${ }^{2}$ The chest drain system used in our unit is the Atrium Ocean (MAQUET Medical Systems, United States). This system has three main chambers-a fluid collection chamber, a chamber with water-seal to monitor degree of air-leak, and a suction control chamber. The safety port valve, which is open to the air, prevents the chest drain system from forming a closed system which might in turn potentially cause tension pneumothorax, especially when suction is not applied. This safety port valve however creates a potential pathway for viral spread from the drainage system. Herein, we suggest modifications to the Atrium chest drain system and describe the subsequent COVID-19 test results from various parts of the system to test the effectiveness of the modifications.

\section{Chest drain system modifications}

We suggest three modifications on the system (Fig 1).

\subsection{5\% Aqueous-based chlorhexidine gluconate solution in water seal chamber}

Kumar et $\mathrm{al}^{3}$ suggested the use of $1 \%$ sodium hypochlorite solution (ie, bleach) to replace the water in the water seal chamber for patients with COVID-19. However, we suggested the use of $0.05 \%$ aqueous-based chlorhexidine gluconate solution, to mitigate the potential risk of chlorine gas leaking back through the system to the patient. This $0.05 \%$ chlorhexidine gluconate solution is as effective as povidone-iodine or $70 \%$ ethyl alcohol against severe acute respiratory syndrome coronavirus 2 (SARS-CoV-2). ${ }^{4}$

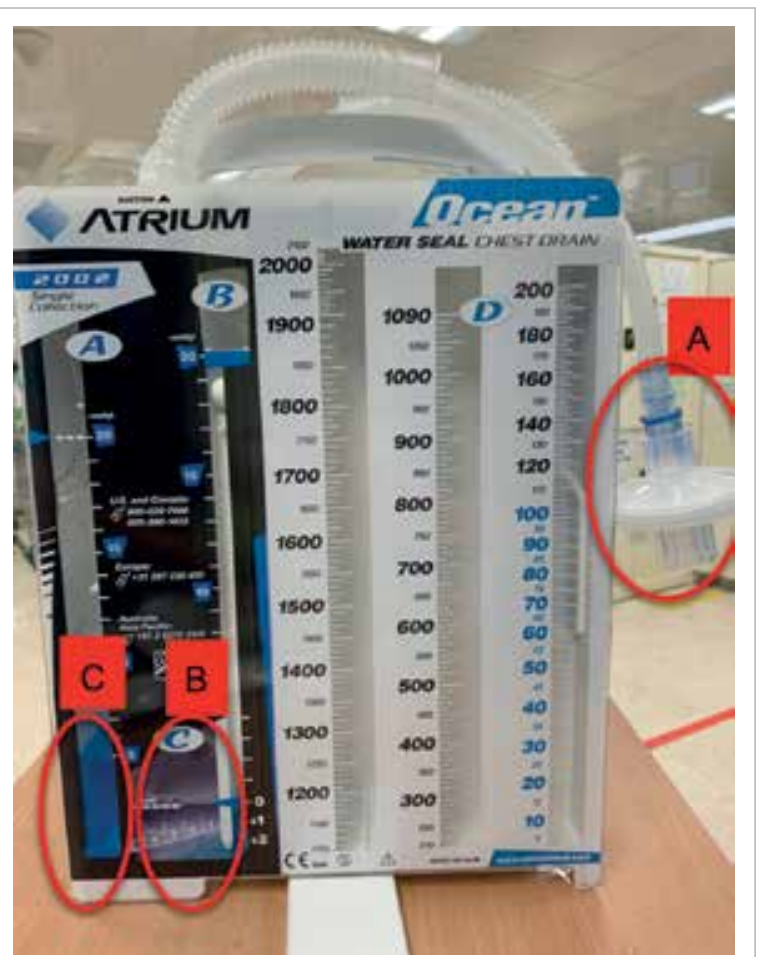

FIG I. A modified Atrium Ocean (MAQUET Medical Systems, United States) chest drain system. (A) Cook adapter and bacterial viral filter, (B) $0.05 \%$ chlorhexidine gluconate solution to replace the water in the water seal chamber, and $(\mathrm{C})$ water added in suction control chamber

\section{Water column in the suction control} chamber to water seal the chamber

Sterile water $(5 \mathrm{~mL})$ was added to the suction control chamber to water seal it, so that excessive gas could not escape the chest drain system through the suction control port. Any excessive air leak to this chamber, if any, could only leak out through the suction port.

\section{Bacterial viral filter at the suction port}

A bacterial viral filter (BVF) has a filtration efficiency rate of $>99.9999 \%$ as tested with particle size of around $3 \mu \mathrm{m}$, which is effectively the size 
of SARS-CoV-2. The filter has a small dead space that minimises rebreathing of carbon dioxide. To connect the BVF to the suction port, the suction control stopcock is disconnected from the suction port. An adapter with diameter $15 \mathrm{~mm}$ from the Cook Airway Exchange (Cook Medical) is then used to connect the suction port to the BVF. If the Cook Airway Exchange adaptor is not available, an adaptor of a 7.5-Fr endotracheal tube is an alternative. The length of the suction port should be such that the filter does not touch the floor, or it might create a closed chest drain system, potentially increasing the risk of tension pneumothorax.

\section{Practical experience}

\section{Sample collection}

The above modified system was connected to a patient with COVID-19 who required mechanical ventilation for his chest infection complicated by pneumothorax. Several swabs from the chest drain system were taken and tested by polymerase chain reaction (PCR) for COVID-19. Swabs were taken from four sites on of the chest drain system (Fig 2). Swabs were taken with the sampling sticks

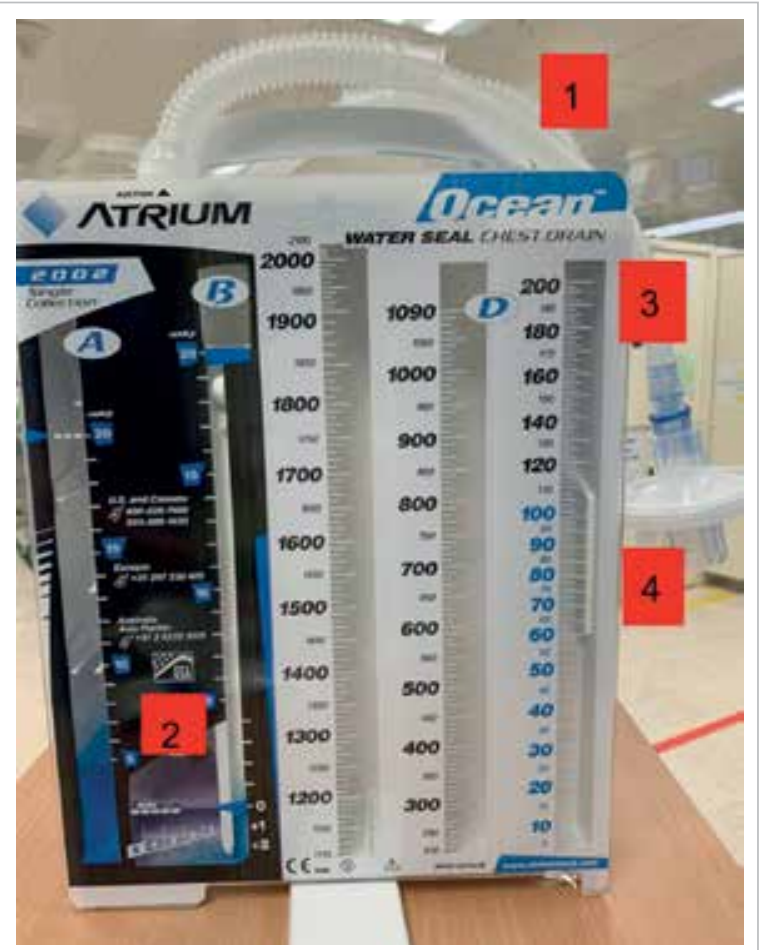

FIG 2. Sampling sites for coronavirus disease 2019 polymerase chain reaction tests. Site I: chest drain tubing immediately connected to patient; Site 2: chlorhexidine gluconate solution from the underwater seal chamber; Site 3: chest drain tubing before the bacterial viral filter; and Site 4: area beyond the bacterial viral filter moistened by sterile water. The sampling sticks were rolled over the sample areas at least 10 times in a circular motion. The swabs were sent to the microbiology laboratory immediately for testing for SARS-CoV-2 using a reverse transcription PCR (RT-PCR) TIB-E-gene test (TIB Molbiol Syntheselabor $\mathrm{GmbH}$, Berlin, Germany) with the corresponding cycle threshold (CT) value. For Site 1, the chest drain catheter was disconnected from the tubing of the chest drain system and the swab was taken from the inside of the tubing. For Site 2, $1 \mathrm{~mL}$ of fluid from water seal chamber was aspirated. For Site 3, the tubing was disconnected from the BVF and the inside of the tubing was swabbed. For Site 4, the surface of the area beyond the BVF was swabbed.

\section{Test results}

For Site 1, testing with SARS-CoV-2 RT-PCR TIB-E-gene was positive and the CT value was 29.51 , compared with the CT value of 16.1 from the tracheal aspirate sample taken in the same patient on the same day. For Sites 2 to 4, SARS-CoV-2 RT-PCR TIB-E-gene tests were all negative.

\section{Discussion}

The results suggested the potential effectiveness of our system. Firstly, COVID-19 was detected in Site 1 (the chest drain catheter), confirming that the virus can potentially spread from a chest drain. Secondly, COVID-19 was not detected in Site 2, suggesting that the $0.05 \%$ chlorhexidine gluconate solution was effective against SARS-CoV-2. This is further supported by the negative COVID-19 result in Site 3. Because the virus was not detected in Site 3 , the negative result in Site 4 does not necessarily demonstrate the efficacy of the BVF in preventing the spread of COVID-19. Nevertheless, although the efficacy of individual modification of the chest drain system could not be demonstrated, the complete system proved to be effective in isolating the virus in the chest drain system.

The number of patients with COVID-19 in Hong Kong has been small, and pneumothorax is not a common presentation for patients with COVID-19. To validate the efficacy of our suggested modifications, further testing of the system is required.

Simple wall suction applied to the system could provide even better safeguard. However, suction is not clinically indicated for all patients with pneumothorax. Furthermore, wall suction cannot be applied during transport of the patient. If suction is clinically indicated, the modified chest drain system can be connected to the wall suction in the usual manner after removing the BVF; the BVF is unnecessary after connection to wall suction because the system is now closed. 


\section{Conclusion}

Our proposed modifications of the chest drain system could potentially prevent the spread of COVID-19 in patients with pneumothorax. Further study is required to confirm the safety and efficacy of these modifications.

\section{Author contributions}

All authors contributed to the concept or design of the study, acquisition of the data, analysis or interpretation of the data, drafting of the manuscript, and critical revision of the manuscript for important intellectual content. All authors had full access to the data, contributed to the study, approved the final version for publication, and take responsibility for its accuracy and integrity.

\section{Conflicts of interest}

All authors have disclosed no conflicts of interest.

\section{Funding/support}

This study research received no specific grant from any funding agency in the public, commercial, or not-for-profit sectors.

\section{Ethics approval}

Research ethics application was waived for this study by the KC/KE Research Ethics Committee. Verbal consent was taken from the patient's relatives. The study conformed to the ethical guidelines of the 1975 Declaration of Helsinki as reflected in a priori approval by the institution's human research committee.

\section{Availability of data and materials}

The data presented in the article can be obtained for studies with aim to test the efficacy of preventing COVID-19 spread by modification of the chest drain system by contacting the corresponding author by email at h0145237@gmail.com within 3 years after this article is published.

\section{References}

1. Duffy C, Kidd A, Francis S, et al. Chest drain aerosol generation in COVID-19 and emission reduction using a simple anti-viral filter. BMJ Open Respir Res 2020;7:e000710.

2. Bilkhu R, Viviano A, Saftic I, Bille A. COVID-19: Chest drains with air leak - the silent 'super spreader'? Available from: https://www.ctsnet.org/article/covid-19-chestdrains-air-leak-\%E2\%80\%93-silent-\%E2\%80\%98superspreader\%E2\%80\%99. Accessed 28 Sep 2020.

3. Kumar N, Kumar A, Kumar A, Kumar S. Coronavirus Disease-2019: modified underwater seal chest drain system. J Cardiothoracic Vasc Anesth 2021;35:347-8.

4. Kampf G, Todt D, Pfaender S, Steinmann E. Persistence of coronaviruses on inanimate surfaces and their inactivation with biocidal agents. J Hosp Infect 2020;104:246-51. 